\title{
Telestroke in Northern Alberta: A Two Year Experience with Remote Hospitals
}

\author{
Khurshid Khan, Ashfaq Shuaib, Tammy Whittaker, Maher Saqqur, \\ Thomas Jeerakathil, Ken Butcher, Patrick Crumley
}

\begin{abstract}
Background: Thrombolysis in acute ischemic stroke is usually performed in comprehensive stroke centres. Lack of stroke expertise in remote small hospitals may preclude thrombolysis. Telemedicine allows such management opportunities in distant hospitals. Methods: We report our experience in managing acute stroke over a two-year time period with telestroke. The University of Alberta Hospital acted as the 'hub' and seven remote hospitals as 'spoke'. The neurologist at the 'hub' provided stroke expertise to the local physician using either a two-way video link or telephone. Cranial CT scans were transmitted to 'hub'. Education sessions were held before the initiation of the program. Results: Of 210 patients $44(21 \%)$ received thrombolysis at the 'spoke' sites. In $34 / 44$ (77\%) two-way video link was available while in 10/44 (23\%) telephone was used. Five (11.4\%) patients experienced intracranial hemorrhage after thrombolysis, 2 (4.5\%) were symptomatic. Favorable (mRS=0-1) outcome at three months was $16 / 40(40 \%)$ and mortality was $9 / 40$ $(22.5 \%)$. Four patients were lost to follow-up. There was no significant three months outcome difference between two-way video link and telephone consultation $(\mathrm{P}=0.689)$. Over two years the number of acute stroke transfers decreased from 144 to 15 at one of the 'spoke' sites, a $92.5 \%$ decline. Conclusion: It is possible to successfully treat patients with acute ischemic stroke at remote sites through videoconferencing or telephone consultation. Telestroke can also lead to a significant reduction in the number of patients requiring transfer to a tertiary care centre.
\end{abstract}

RÉSUMÉ: Télé-AVC dans le nord de l'Alberta : une expérience de deux ans dans des hôpitaux situés en région éloignée. Contexte : La thrombolyse dans l'accident vasculaire cérébral (AVC) ischémique aigu est habituellement effectuée dans des centres intégrés de soins de l'AVC. Le manque d'expertise dans le domaine de l'AVC dans les petits hôpitaux situés en région éloignée est un obstacle à la thrombolyse. La télémédecine permet d'y pallier dans les hôpitaux situés en région. Méthodologie : Nous rapportons notre expérience dans la prise en charge de l'AVC aigu au cours d'une période de deux ans au moyen de télé-AVC. Le University of Alberta Hôpital a agi comme noeud central et plusieurs hôpitaux situés en région comme sites satellites. Le neurologue du noeud central fournissait l'expertise en AVC au médecin local au moyen soit d'un lien vidéo à deux directions ou du téléphone. Les tomodensitométries cérébrales étaient transmises au noeud central. Des sessions de formation étaient tenues avant le début du programme. Résultats : Quarante-quatre (21\%) des 210 patients ont reçu une thrombolyse dans les sites satellites. Pour 34 d'entre eux (77\%), un lien vidéo à deux directions était disponible alors que pour $10(23 \%)$ le téléphone a été utilisé. Cinq patients $(11,4 \%)$ ont subi une hémorragie intracrânienne après la thrombolyse. Deux patients $(4,5 \%)$ étaient asymptomatiques. Une issue favorable $(\mathrm{mRS}=0-1)$ à trois mois a été observée chez 16 patients (40\%) et la mortalité a été de 9 (22,5\%). Quatre patients ont été perdus de vue. Il n'y avait pas de différence dans l'issue à 3 mois entre le lien vidéo à deux directions et la consultation par téléphone $(\mathrm{p}=0,689)$. Sur une période de deux ans, le nombre de transferts de patients atteints d'AVC aigu a diminué de 144 à 15 à l'un des sites satellites, une diminution de 92,5\%. Conclusion : Il est possible de traiter avec succès des patients atteints d'AVC ischémique aigu en région éloignée par vidéoconférence ou consultation téléphonique. Télé-AVC peut également entrainer une diminution significative du nombre de patients qui doivent être transférés à un centre de soins tertiaires.

Can. J. Neurol. Sci. 2010; 37: 808-813

Stroke is a common neurological emergency and remains a major cause of short and long-term disability worldwide ${ }^{1}$. Thrombolysis with intravenous tissue plasminogen activator (tPA) can result in a significantly better outcome if the treatment is offered early ${ }^{2}$. Despite evidence from several studies showing consistently better results in tPA treated patients, less than $8 \%$ of ischemic stroke patients receive intravenous $\mathrm{tPA}^{3,4}$. Many factors contribute to the relatively low rate of intravenous tPA treatment. Among them late arrival to a comprehensive stroke centre is a major factor. In the NINDS trial over 16000 stroke victims were screened and among them $50 \%$ arrived too late to be treated ${ }^{5}$. Late arrival to hospital is particularly important in countries where the population is spread over a large geographical area.
Telemedicine allows stroke specialists and physicians at distant hospitals to work together in improving patient care ${ }^{6}$. Telemedicine provides an opportunity to optimize acute stroke treatment regardless of the geographical location. A large telemedicine based study has shown comparable safety and

From the Division of Neurology (KK, AS, MS, TJ, KB), Department of Medicine; University of Alberta Hospital (TW), Edmonton; Northern Alberta Telestroke Program (PC), Camrose, Alberta, Canada.

Received October 23, 2009. Final Revisions Submitted May 17, 2010. Correspondence to: Khurshid Khan, 2E3 WMC, Division of Neurology, University of Alberta Hospital, Edmonton, Alberta, T6G 2B7, Canada. 
efficacy results in acute stroke patients treated with intravenous tPA via telemedicine conference using video and audio linkage ${ }^{7}$. Their findings suggested that physicians with little experience in treating acute stroke with thrombolytic agent, when guided remotely via telemedicine by stroke experts, could achieve comparable results to tertiary centres ${ }^{7}$. A recent randomized control study comparing videoconferencing with computed tomography (CT) image review to telephone consultations without CT image review showed similar outcome at 90 days ${ }^{8}$. Other smaller studies have also published encouraging results ${ }^{9-16}$.

In this report, we present our experience with telemedicine over a two year time frame in Northern Alberta.

\section{METHODS}

We collected data on all consecutive patients with acute ischemic stroke who were referred to the telestroke program and received thrombolysis. The Northern Alberta Stroke Program provides stroke expertise to a population of over 1.5 million people spread over a large geographical area. A distance of more than $100 \mathrm{~km}$ from the University of Alberta Hospital does not allow the majority of patients to be transferred within the therapeutic window to receive thrombolysis. Using the 'hub' and 'spoke' model, in March of 2007, we implemented the telemedicine program where four non-tertiary hospitals with CT scans were approached to become part of the acute telestroke program. These sites were equipped with a two-way videoconferencing system. In addition three other centres were recruited using telephone consultation where video linkage was not available. Acute stroke management training sessions were held with physicians and nursing staff at these hospitals. Standard stroke protocols currently in use at the University of Alberta stroke centre (hub) were established at these hospitals (spokes). The distances from the 'spoke' to the 'hub' varied between 100 and 400 kilometers. The emergency department physician at the 'spoke' consulted the stroke neurologist through the critical care line for any suspected stroke patient who presented within six hours of symptoms onset. If a patient was deemed eligible for thrombolysis, the telestroke two-way video consultation would be initiated. This allowed direct communication and examination of the patients by the stroke neurologist along with the local physician. Cranial CT scans were transmitted securely on high speed internet to the 'hub' picture archiving and communication system (PACS). The method of interpretation of CT scan using either ASPECT (Alberta Stroke Program Early CT) or 1/3 middle cerebral artery rule depended on the preference of the stroke neurologist. The service was available 24 hours at the 'spokes'. Similarly a dedicated round-the-clock telestroke pager was established at the 'hub'. Five stroke neurologists covered the telestroke call on rotation. Post thrombolysis CT scan was obtained within 24 hours and the patient was again assessed either through two-way videoconferencing where it was felt necessary or only telephone discussion was held with the local physician. Patients were monitored as per current stroke thrombolysis protocol in the emergency department or in the intensive care unit for 24 hours and then would be transferred to general medical ward for further management. None of the 'spokes' had designated stroke units. Pre-existing local resources were utilized for post stroke rehabilitation.
Pre-thrombolysis National Institute of Health Stroke Scale (NIHSS) was documented. Whenever possible, follow-up NIHSS scores was recorded 24 hours after treatment. Information gathered also included the time from onset of symptoms to arrival at the local emergency department, the time from arrival to completion of CT scans, and door to needle time. At three remote hospitals where video link was not available, we reviewed the patient's history with the referring physician on the telephone and either accessed the cranial CT scans directly or relied on the local radiologist if scans could not be transmitted immediately to the 'hub'. Clinical data, especially the NIHSS were difficult to collect in patients with telephone consultation. Finally, three months modified Rankin Scale (mRS) was obtained through the telephone call either directly from the patient or from the caregiver. A favorable outcome at three months was considered to be mRS score of less than 3 . The main objectives of this analysis were to determine the number of patients who were thrombolysed and the outcome of treatment at three months. Prior to the initiation of the telestroke service, most of the patients were being transferred from the 'spoke' to the 'hub'. One additional objective of this study was to evaluate the impact of the availability of the telestroke service on the transfer of patients and cost savings from one of the 'spokes' to the 'hub'.

Our telestroke program uses a Tandberg Edge 95 videoconference system that utilizes a high definition camera and views far end images on a 32 inch LCD monitor for greater resolution and the system is capable of participating in calls up to $2 \mathrm{Mbps}$ on the broadband internet.

\section{RESULTS}

During the first two years of the program, the telestroke program was activated 210 times. Forty four (21\%) of these were considered candidates for thrombolysis after interview of the patient and family members, physical examination and review of the brain imaging. The remaining 166 out of $210(79 \%)$ patients were excluded from the analysis (Table 1).

The details of the 44 patients treated with intravenous tPA are presented in Table 2. Thirty-four (77\%) of these patients were examined through telestroke video link. In the remaining 10 (23\%), the 'spoke' did not have video facilities and the decision of thrombolysis was made over telephone consultation with local physician. The NIHSS score was available mostly for patients who were assessed through the telestroke video link compared to only telephone consultation. The three months mRS was obtained for $40 / 44(91 \%)-4(9 \%)$ patients were lost to followup. Sixteen of $40(40 \%)$ patients had an mRS of less than 2 (Figure). Ten (25\%) patients had $\mathrm{mRS}$ of 2 at three months. Three months mRS did not show significant difference between the patients treated through telestroke two-way video link and telephone consultation $(\mathrm{P}=0.689)$

Nine patients $(22.5 \%)$ died within three months of thrombolytic treatment. Seven of the nine patients were $>$ the age of 80 - two were over 90 years of age (Table 3). Four deaths occurred early, within a week of thrombolysis. In two of them, the repeat CT showed cerebral hemorrhage - in one the hemorrhage was in a remote region. The third patient had preexisting severe cardiac disease and suffered very early massive aspiration that likely contributed to the patient's death. This 
Table 1: Patients who were not eligible for thrombolysis

Diagnosis

Number of patients

1. Rapid improvement

52

2. Symptom onset beyond time window

3. Non-stroke mechanism for neurological symptoms

54

4. Intracerebral hemorrhage

10

5. Sub arachnoid hemorrhage

3

Total

166

patient did not have follow up CT at family's request. Similarly the fourth patient, a 93-year-old female had a significant deterioration in the initial 24 hours with her NIHSS score increasing from 27 to 38 and died within three days. This patient did not have a repeat scan at the request of family. In the remaining five patients death occurred 8 to 90 days following the acute ischemic stroke, likely secondary to the large ischemic stroke or unrelated causes. Five $(11.4 \%)$ patients had cerebral hemorrhage on the repeat CT scan within 24-36 hours post thrombolysis. Clinical worsening was seen in two $(4.5 \%)$ of the five patients who died within two and eight days respectively from the onset of symptoms. In the other three patients, the repeat CT scan showed small hemorrhage within the region of the cerebral infarction without clinical worsening. The clinical worsening was defined as any deterioration that was felt to be significant by the 'spoke' physician or $>4$ points increase in NIHSS. In total three patients did not have follow-up CT scans at the request of families. The exact mechanism for death, including the possibility of a symptomatic hemorrhage, cannot be excluded.

Twelve $(27 \%)$ patients received thrombolysis beyond the three hours window. Our largest 'spoke' site had 23/44 (52\%) of the intravenous tPA treated patients. This represented $17.6 \%$ of patients admitted to the hospital with a diagnosis of ischemic stroke. The average length of stay for the treated patients was three days compared to seven days for patients not treated with tPA. This resulted in a reduction of 1015 fewer days for patient care. At a daily cost of $\$ 903$ Canadian, the cost saving was estimated at $\$ 916,545$ at this site. In the year prior to the implementation of the telestroke program at this site, 144 patients were transferred to University of Alberta Hospital. During the second year of the availability of the telestroke service, this number decreased to only 15 patients, a $92.5 \%$ change.

\section{Discussion}

Telemedicine provides the medium for real time assessment of the patient and face-to-face management discussion with ER physician, nursing staff and family members by a stroke expert from a tertiary centre. Telemedicine can avert the need for transporting the patient to a tertiary stroke centre and save extremely valuable time for initiation of treatment. Our experience over the last two years reveals that with minimal training the medical personnel at the non-tertiary emergency departments treated $21 \%$ of patients with intravenous tPA with generally comparable outcome to historical control. The 'doorto-needle' times were acceptable and the risk of symptomatic cerebral hemorrhage was similar to reports in the literature ${ }^{8-16}$. The 90-day mortality was also comparable to published

Table 2: Details of the 44 patients treated with thrombolysis over a two year time period

\begin{tabular}{|c|c|c|c|}
\hline & Telestroke Video Consults $(n=34)$ & Telestroke Phone Consults $(\mathrm{n}=10)$ & P value \\
\hline Number of patients receiving thrombolysis & $34 / 44$ & $10 / 44$ & \\
\hline Mean Age & 70 (range 21-93) & 61 (range 20-86) & 0.6 \\
\hline Number of Male Patients & $20(59 \%)$ & $4(40 \%)$ & 0.4 \\
\hline Mean time of onset to ER & 92 min (range $18-210)$ & 102 min (range 24-171) & 0.68 \\
\hline Mean time from CT to tPA & 60 (range 6-122) & 56 (range $25-85$ ) & 0.75 \\
\hline Mean Door to Needle & 82 (range $40-195)$ & 77 (range $27-146$ ) & 0.46 \\
\hline Mean time of onset to tPA & 171 (range $88-330$ ) & 179 (range $115-260)$ & 0.76 \\
\hline Pre thrombolysis NIHSS (Median) & 16 (range $3-37$ ) & 19 (range $6-22$ ) & 0.4 \\
\hline 24 Post thrombolysis NIHSS Median & 3 (range $0-39)(20 / 34)$ & 2 (Available for only one) & \\
\hline
\end{tabular}


reports $^{8-16}$. Finally, we observed that treatment through the telestroke program resulted in a significant decrease in the transfer of patients from the local hospitals to the tertiary care facility.

Telemedicine is an emerging field and has been used successfully in patients with heart disease ${ }^{17}$, intensive care treatment $^{18}$ and a variety of other acute illnesses ${ }^{6}$. For management of acute stroke, telemedicine is relatively new technology. A handful of sites have published their experience over the last five years ${ }^{8-16}$. While most sophisticated programs require the two-way videoconference with access to real time viewing of the cranial CT scans, there is also experience where the CT images are reviewed locally by the radiologist and the telephone consultation occurs with no direct visual examination of the patient through videoconferencing ${ }^{8}$. A randomized controlled trial comparing telephone consultations to a direct video link has shown that significantly more patients are misdiagnosed when the patient is not examined through the video link ${ }^{8}$. However, the outcome is no different for the two types of assessments for patients treated with intravenous tPA ${ }^{8}$. In 10 of our 44 patients, treatment was initiated after the telephone consultation and the outcome did not appear to be significantly different from where the assessment was done through the video link.

The number of patients with acute stroke who have had intravenous tPA through telestroke consultations is small ${ }^{8}$. The largest series for successful use of telemedicine in treating acute stroke comes from Germany ${ }^{12}$. In Bavaria, the TEMPiS program consisted of 2 'hubs' and 12 'spokes' and over a 20-month time period treated 86 patients with intravenous tPA out of 396 consultations. In the only other published series with more patients than our study, the STRokE DOC study treated 56 patients with intravenous tPA, equally randomized to video link and telephone consultation. Other centres have published their experience with a limited number of patients varying from 1 to 30 intravenous tPA treated patients (Table 4). In Canada, the Ontario telehealth network has published its experience with two 'hub' and two 'spoke' sites where over a 34 month time period 27 out of $88(30 \%)$ patients were treated with tPA in the telestroke program ${ }^{15}$.

A number of shortcomings require discussion. In our series, there were seven 'spoke' (four with videoconferencing and three with only phone consultation) for a single 'hub' and from very early into initiation of the program we realized that there was

Table 3: Details of the nine patients who died within 90-days after thrombolysis

\begin{tabular}{|c|c|c|c|c|c|c|c|c|}
\hline Sex & Age & $\begin{array}{l}\text { NIHSS } \\
\text { Pre } \\
\text { tPA }\end{array}$ & $\begin{array}{l}\text { NIHSS } \\
\text { Post } \\
\text { tPA }\end{array}$ & $\begin{array}{l}\text { Onset } \\
\text { to tPA }\end{array}$ & Pre thrombolysis CT & $\begin{array}{l}\text { Post thrombolysis } \\
\text { CT (24-36 hrs) }\end{array}$ & $\begin{array}{l}\text { Onset to } \\
\text { Death }\end{array}$ & Remarks \\
\hline Male & 59 & 22 & 32 & $2 \mathrm{hrs}$ & No acute abnormality & $\begin{array}{l}\text { Symptomatic } \\
\text { Hemorrhage in a } \\
\text { remote site }\end{array}$ & $48 \mathrm{hrs}$ & $\begin{array}{l}\text { Due to significant premorbid health status, } \\
\text { including malignancy, conservative management } \\
\text { was undertaken after thrombolysis }\end{array}$ \\
\hline Female & 66 & 19 & N/A & $2 \mathrm{hrs}$ & $\begin{array}{l}\text { Right MCA dense sign. } \\
\text { No appreciable ischemic } \\
\text { changes }\end{array}$ & $\begin{array}{l}\text { Large right MCA } \\
\text { stroke with midline } \\
\text { shift. Hyper dense } \\
\text { MCA sign }\end{array}$ & 8 days & Due to stroke complications \\
\hline Female & 86 & 22 & N/A & $\begin{array}{l}2 \mathrm{hrs} 42 \\
\min \end{array}$ & No acute abnormality & $\begin{array}{l}\text { Not done - palliative } \\
\text { measures }\end{array}$ & 15 days & Aspiration Pneumonia \\
\hline Female & 84 & 3 & 0 & $\begin{array}{l}2 \mathrm{hrs} \\
22 \mathrm{~min}\end{array}$ & $\begin{array}{l}\text { Leukoariosis, no acute } \\
\text { infarct }\end{array}$ & $\begin{array}{l}\text { No evidence of } \\
\text { hemorrhage }\end{array}$ & $\begin{array}{l}3 \text { months } \\
\text { after stroke }\end{array}$ & Unrelated causes \\
\hline Male & 83 & 37 & 39 & $\begin{array}{l}3 \mathrm{hrs} \\
10 \mathrm{~min}\end{array}$ & $\begin{array}{l}\text { Old left cerebellar and } \\
\text { right occipito-parietal } \\
\text { infarcts. Very early mild } \\
\text { left MCA ischemic } \\
\text { changes }\end{array}$ & $\begin{array}{l}\text { Moderate size left } \\
\text { MCA infarct with } \\
\text { hemorrhagic } \\
\text { conversion. Clinical } \\
\text { worsening - } \\
\text { symptomatic } \\
\text { hemorrhage }\end{array}$ & $\begin{array}{l}3 \text { days post } \\
\text { thrombolysis }\end{array}$ & Related to stroke \\
\hline Male & 91 & 24 & 12 & $\begin{array}{l}2 \mathrm{hrs} \\
12 \mathrm{~min}\end{array}$ & No acute abnormality & $\begin{array}{l}\text { Asymptomatic } \\
\text { Hemorrhagic } \\
\text { Conversion in the } \\
\text { ipsilateral right basal } \\
\text { ganglia }\end{array}$ & 30 days & No worsening of neurological status \\
\hline Female & 80 & 22 & 8 & $4.5 \mathrm{hrs}$ & No acute infarct & $\begin{array}{l}\text { Small subcortical } \\
\text { infarct in the left } \\
\text { MCA distribution }\end{array}$ & $\begin{array}{l}15 \text { day post } \\
\text { first stroke }\end{array}$ & $\begin{array}{l}\text { Recurrence of massive left MCA stroke } 7 \text { days after } \\
\text { first stroke - stroke related complications }\end{array}$ \\
\hline Female & 87 & 12 & 17 & $\begin{array}{l}1 \mathrm{hr} 21 \\
\min \end{array}$ & $\begin{array}{l}\text { No acute abnormality. } \\
\text { Old parieto-occipital } \\
\text { watershed infarct }\end{array}$ & $\begin{array}{l}\text { Not done as palliative } \\
\text { measures were } \\
\text { decided }\end{array}$ & Within 24 hrs & Massive Aspiration Pneumonia \\
\hline Female & 93 & 27 & 38 & $3 \mathrm{hrs}$ & No acute abnormality & $\begin{array}{l}\text { Not done at family's } \\
\text { request - palliative } \\
\text { measures }\end{array}$ & $\begin{array}{l}\text { Within } 3 \\
\text { days post } \\
\text { thrombolysis }\end{array}$ & $\begin{array}{l}\text { Due to stroke complications - CHF/pulmonary } \\
\text { edema }\end{array}$ \\
\hline
\end{tabular}


Table 4: Telestroke experience from the reports published to date

\begin{tabular}{llcccc}
\hline Site & No. tPA & onset to tPA & ED arrival to tPA & \% receiving tPA & No. of consultations \\
\hline Alberta & 44 & 171 & 82 & $21 \%$ & 210 \\
TEMPiS $^{(7)}$ & 86 & N/A & 78 & $22 \%$ & 396 \\
STRokE DOC $^{(8)}$ & 56 & 151 & 110 & $25 \%$ & 223 \\
REACH $^{(13)}$ & 30 & 111 & 105 & $16 \%$ & 194 \\
Ont Network $^{(16)}$ & 27 & N/A & N/A & $30 \%$ & 88 \\
Houston $^{(9)}$ & 14 & N/A & 85 & N/A & N/A \\
STARR $^{(10)}$ & 10 & 158 & 124 & $30 \%$ & 33 \\
PTC $^{(11)}$ & 6 & 124 & 106 & $33 \%$ & 24 \\
TESS $^{(14)}$ & 2 & N/A & N/A & $1 \%$ & 153 \\
\hline
\end{tabular}

considerable variability in the utilization of the telestroke program from various 'spoke' sites. We were unable to determine if any thrombolysis eligible patients were missed or not considered for possible treatment at different 'spoke' sites. It was not always possible to get complete NIHSS evaluations. This was especially evident at the sites with telephone consultation where direct two-way videoconferencing was not available. This is similar to the results from the STRokE DoC experience ${ }^{8}$. Another shortcoming is that 90 day information is missing on four (9\%) patients. Repeated attempts through the telephone failed to reach the patients or their caregivers perhaps reflecting the reality of practice outside controlled trials.

There were nine deaths in our 44 patients. While symptomatic cerebral hemorrhage was the likely cause of death in two patients, it is possible that it may have contributed to the patient's demise in an additional three cases where we could not obtain post thrombolysis CT scan as mentioned above. Assuming worst case scenario the rate of symptomatic intracranial hemorrhage would be $11.4 \%$ (5/44). However, it seems less likely because these patients clearly had obvious non-neurological complications. Most of the patients who died were elderly. Seven of the nine patients were $>80$ years old and two were over 90 years of age. There is paucity of randomized data on tPA treatment of elderly population aged 90 and above. A recent retrospective study showed poor prognosis with thrombolysis in patients over the age of 90 with over $80 \%$ of patients dying within 90 days of therapy ${ }^{19}$. We could also not determine the effect of initiation of the telestroke program on patient transfers from 'spoke' to the 'hub' except one. This site however represented the largest catchment area and shows a dramatic reduction (more than 90\%) of patient transfers to the tertiary care centre and a reduction of admission days (from 7 to 3 days).

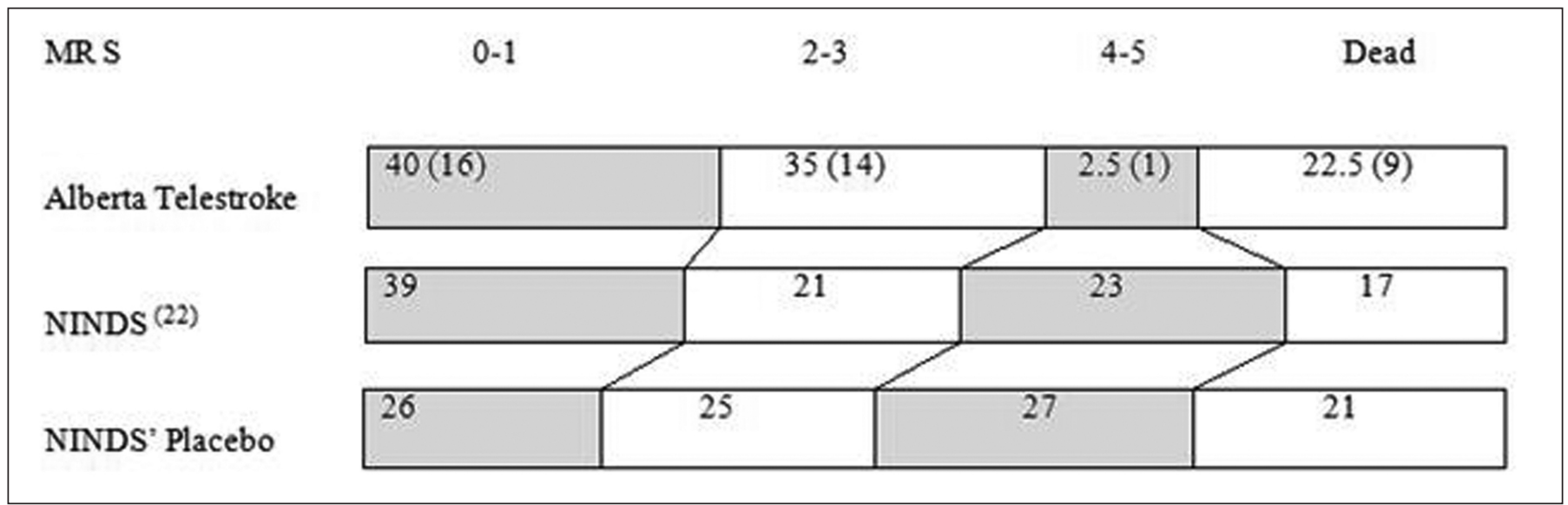

Figure: Modified Rankin scale (MRS) at three months - percentage of patients 


\section{Conclusions}

To summarize, we report our experience with telestroke medicine over a two year time period in Northern Alberta. Over $21 \%$ of consultations resulted in treatment with intravenous tPA. Our door to needle times and outcomes are comparable to registries that have published their experience from North America and Europe ${ }^{20,21}$. We believe the addition of a robust telestroke service is possible with very little additional investment and can provide a much-needed service to communities where thrombolytic treatment of stroke patients may otherwise not be possible.

\section{ACKNOWLEDGEMENTS}

The authors thank the medical staff at the participating sites for their help.

\section{REFERENCES}

1. Murray CJ, Lopez AD. Global mortality, disability, and the contribution of risk factors: global burden of disease study. Lancet. 1997;349:1436-42.

2. The ATLANTIS, ECASS, and NINDS rt-PA Study Group Investigators. Association of out come with early stroke treatment: pooled analysis of ATLANTIS, ECASS, and NINDS rt-PA stroke trials. Lancet. 2004;363:768-74.

3. Reeves MJ, Arora S, Broderick JP, Frankel M, Heinrich JP, Hickenbottom S, et al. Acute stroke care in the USA: results from four pilot prototypes of the Paul Coverdell National Acute Stroke Registry. Stroke. 2005;36:1232-40.

4. Kapral MK, Laupacis A, Phillips SJ, Silver FL, Hill MD, Fang J, et al. Stroke care delivery in institutions participating in the registry of the Canadian stroke Network. Stroke. 2004;35:1756-62.

5. Tilley BC, Lyden PD, Brott TG, Lu M, Levine SR, Welch KMA, et al. NINDS and stroke rt-PA Study Group. Total quality improvement method for reduction of delays between emergency department admission and treatment of acute ischemic stroke. Arch Neurol. 1997;54:1466-74.

6. Zajtchuk R, Gilbert GR. Telemedicine: a new dimension in the practice of medicine. Dis Mon. 1999;45:197-262.

7. Audebert HJ, Kukla C, Clarmann von Claranau S, Kühn J, Vatankhah B, Schenkel $J$, et al. Telemedicine for safe and extended use of thrombolysis in stroke: the Telemedic Pilot Project for Integrative Stroke Care (TEMPiS) in Bavaria. Stroke. 2005;36:287-91

8. Meyer BC, Roman R, Hemmen T, Obler R, Ziven JA, Rao R, et al. Efficacy of site-independent telemedine in the STRokE DOC trial. A randomized, blinded, prospective study. Lancet Neurol. 2008;7:787-95.
9. Choi JY, Porche NA, Albright KC, Khaja AM, Ho VS, Grotta JC. Using telemedicine to facilitate thrombolytic therapy for patients with acute stroke. Jt Comm J Qual Patient Saf. 2006;32:199-205.

10. Miley ML, Olmstead NL, Bobrow BJ, Damearchalk BM. The state of emergency stroke resources and care in rural Arizona. Cerebrovasc Dis. 2008;25 (Suppl 2):101.

11. Schwamm LH, Rosenthal ES, Hirshburg A, Schaefer PW, Little EA, Kvedar JC, et al. Virtual telestroke support for the emergency department evaluation of acute stroke. Acad Emerg Med. 2004; 11:1193-7.

12. Audebert HJ, Schenkel J, Heuschmann Pu, Bogdahn U, Haberl RL. Effects of the implementation of a telemedical stroke network: the Telemedic pilot project for integrative stroke care (TEMPiS). Lancet Neurol. 2006;5:742-8.

13. Hess DC, Wang S, Hamilton W, Lee S, Pardue C, Waller JL, et al. Clinical feasibility of a rural telestroke network. Stroke. 2005;36: 2018-20.

14. Wiborg A, Widder B. TESS study group. Teleneurology to improve stroke care in rural areas. The telemedicine in stroke in Swabia (TESS) project. Stroke. 2003;34:2951-56.

15. Waite K, Silver F, Jaigobin C, Black S, Lee L, Murray B, et al. Telestroke: a multi-site, emergency-based telemedicine service in Ontario. J Telemed Telecare. 2006;12(3):141-5.

16. Lamonte MP, Bahouth MN, Hu P, et al. Telemedicine for acute stroke. Triumphs and pitfalls. Stroke. 2003;34:725-8.

17. Morguet AJ, Kuhnelt P, Kallel A, Rauch U, Schultheiss H-P. Utilization of telemedicine by heart disease patients following hospitalization. J Telemed Telecare. 2008;14:178-81.

18. Groves RH, Holvomb BW, Smith ML. Intensive care telemedicine: evaluating a model for proactive remote monitoring and intervention in critical care medicine. In: Latifi R, editor. Current principles and practice of telemedicine and e-Health. Amsterdam: IOS Press; 2008. p.131-46.

19. Mateen FJ, Majeed AN, Spencer BR, Freeman WD, Shuaib A, Demaerschank BM, et al. Outcomes of intravenous tissue plasminogen activator for acute ischemic stroke in patients aged 90 years or older. Mayo Clin Proc. 2009;84:334-8.

20. Hill MD, Buchan AM. Thrombolysis for acute ischemic stroke: results of the Canadian Alteplase for Stroke Effectiveness Study (CASES) investigators. CMAJ. 2005;172:1307-12.

21. Wahlgren N, Ahmed N, Dávalos A, Ford GA, Grond M, Hacke W, et al. Thrombolysis with Alteplase for acute ischemic stroke in the safe implementation of thrombolysis in stroke-monitoring study (SITS-MOST): an observational study. Lancet. 2007;369: 275-82.

22. The National Institute of Neurological Disorders and Stroke rt-PA stroke study group. Tissue plasminogen activator for acute ischemic stroke. N Engl J Med. 1995;333:1581-7. 